\title{
Enhancing Productivity by Enabling a Value-Chain Orientation
}

\author{
Rajesh Shankar Priya ${ }^{*}$, Steffen Ihlenfeldt ${ }^{2}$ \\ ${ }^{1}$ Fraunhofer Institute for Machine Tools and Forming Technology, Noethnitzer Strasse, Dresden, Germany \\ ${ }^{2}$ Chair of Machine Tools Development and Adaptive Controls, Technical University of Dresden, Dresden, Germany
}

ABSTRACT: Automobile Industries constantly face challenges of production stoppages resulting in huge losses. This is often due to supply issues resulting in non-availability of material at the right time, in-full and at the right location. The demand variability from the customer's downstream processes causes several planning issues to the supplier that often leads to decline in customer service levels, lower efficiency and higher costs. This paper will address inter-firm planning process that facilitate material suppliers to manage demand variability and subsequently increase productivity in an end-end value chain planning process using supply chain segmentation principles.

KEYWORDS: Productivity; Performance; Value-Chain

https://doi.org/10.29294/IJASE.5.4.2019.1125-1131

(c) 2019 Mahendrapublications.com, All rights reserved

\section{INTRODUCTION}

Demand- Supply mismatch in automobile industry often results in production stoppages leading to poor customer service levels among the suppliers. In order to avoid the supply issues, companies often overstock the materials to meet the demand of the customer, leading to higher costs to the entire supply chain reducing the overall productivity of the supply chain. Despite numerous efforts are taken by suppliers to forecast demand that can guarantee a stellar level of customer service, they consistently face obstacles in planning due to volatility and variability of demand [1]. In a study conducted by the Gartner group of companies [2], $80 \%$ of respondents relayed that demand variability and forecast accuracy were the main attributes within the supply chain function that leads to decline in customer service, lower efficiency in planning and higher costs. Demand variability is undoubtedly the main challenge in the supply chain efficiency [3]. In the case of no variability in demand, the planning within the supply chain can be controlled with maximum efficiency and ease. However, in an ever-growing and a competitive environment like the automobile industry, the suppliers managing the demand variability can gain a competitive advantage over its competitors. In order to successfully manage any demand variability, the supplier requires a superior planning process that can ensure that the supply capacity is available to meet the required demand [4]. The overarching strategy is not mitigating demand variability but managing demand variability using an integrated inter-firm planning process.

\section{INTEGRATED PLANNING PROCESS}

In an integrated planning process there is higher visibility of the supply chain in the value-chain that facilitate the sales and operations teams at companies to track and relay demand fluctuations on-line to the upstream processes without delay, minimizing the bullwhip effect [5]. Currently, on a decentralized planning process, companies often forecast demand based on historic data leading to minimal flexibility in managing demand. The companies pre-define inventory safety stocks and set reorder levels based on the historic data [6]. In this context, there is a significant dependence of the safety stock for providing the necessary stocks on any demand that is placed in the supply chain. As the relationship co-efficiency between service levels and demand fulfilment is exponential, the companies often keep more stocks than required to meet the demand and end up in huge losses [7]. Hence an integrated planning process is required to define such customer levels that are visible to the entire value-chain. As illustrated in Figure 1, an integrated planning process is advocated benefitting the suppliers by giving responsibility of managing the stocks owned by the customers and facilitates continuous replenishment with collaborative planning and forecasting based on actual demand. In this scenario the maximum and minimum demand for a specific stock keeping unit (SKU) will be identified and the company is liable to keeping the SKU replenished but not overload, as long as the demand is with-in the identified limit [8]. In order to enhance the delivery performance or productivity, it is crucial that the bullwhip effect caused by the upstream processes is minimised. In this proposed integrated planning process, the downstream demand or the end customer demand is considered that facilitates optimal replenishment for the entire value-chain.

\subsection{Barriers of Integrated Planning Process}

An integrated planning process has a distinct barrier in form of IT integration [9]. Companies have internal processes that work with different internal business units using multiple ERP systems. In this scenario any external integration becomes a challenge in terms of data security and standardisation of

*Corresponding Author: rajesh.shankar.priya@iwu.fraunhofer.de

Received: 10.03.2019 Accepted: 10.04.2019 Published on: 27.05.2019


software platforms. In this paper, the conceptual model is built on the integrated IT platforms. On one hand, the realization of such an integrated platform with two companies integrating their planning process in to single set of information flow seems to be highly impossible, firms like IKEA, Dell and ZARA have transitioned successfully from a decentralized planning to an integrated planning strategy (10).

\subsection{Actions required for an Integrated Planning} Process

The firms involved in an integrated planning process must undergo restructuring plans such as postponement strategy [9]. The postponement strategy or delayed configuration methodis a concept that companies can use to extend their production and distribution by the measure of the lead-time and the configurations can be delayed accordingly if the leadtime is short or prioritized if it is longer [10]. As shown in Figure 2, the location and the form of the inventory can determine the manufacturing strategy. In a Build to Order (BTO) strategy, the supplier holds no direct inventory due to the parse order pattern of products. A longer lead time is foreseen in such a strategy but as the products are rarely in need, storing these products in inventory will result in huge losses. However, in a
Make to Stock (MTS) strategy, inventory is held locally regardless of the demand and it is ready to be shipped on arrival of the demand. Regardless of the manufacturing strategies, all these configurations are dependent of a higher level of forecast accuracy to minimize overstocks or eliminate no-stock scenario [11]. The productivity of the supply chain depends entirely on the type of the inventory the company holds. The value of the inventory can be increased if the manufacturing strategy is based on responsiveness or the same inventory can be reduced if the companies opt for flexibility. Hence, it is crucial for companies to jointly collaborate with its suppliers in determining the manufacturing strategies for every single product to enhance the over-all productivity of the value-chain. In the context of the automobile industries, a high degree of responsiveness and flexibility to guarantee delivery performance on one side, whilst reducing the costs on the other. This research paper will develop a model based on supply chain segmentation principles that will facilitate companies to organize their manufacturing strategies based on actual demand. The rationale of using segmentation principles is to segment products that cannot have a bad service line versus a product that can be consolidated in service levels.

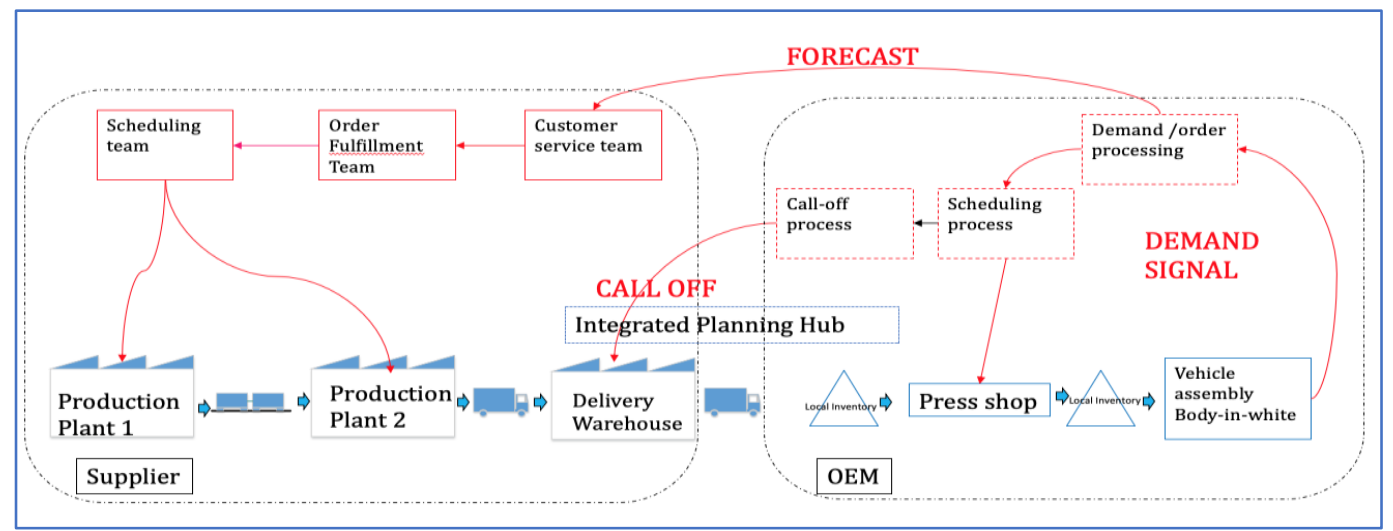

Figure 1 Integrated Planning Hub

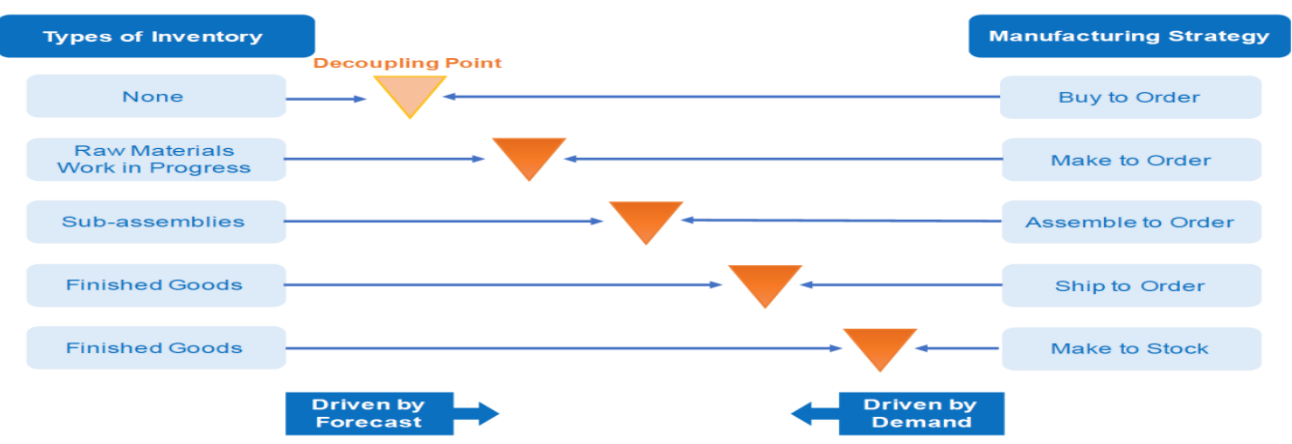

Figure 2 Postponement Strategy adapted from [18]

\section{SUPPLY CHAIN SEGMENTATION}

Often companies have a single defined strategy for differentiated customer groups creating operational bottlenecks and generating unnecessary waste. The supply chain segmentation is a process of dividing the supply chain in to distinct segments that can have different supply chain strategies and practices, enabling efficient management capabilities and creating value to customers [12]. The concept of market segmentation was established in 1950's [13] as businesses started to 
focus either on cost leadership or product differentiation. In the current generation, the companies have recognised that that "one-size-fits all" strategy is not suitable for dealing with customers and the segmentation principles are based not only on products, customers and markets but also in demand data [14]. The products can be segmented as functional and innovative based on different demand patterns [15]. A product is termed to be functional when the demand of that product is stable and predictable. However, highly flexible product portfolios offer businesses higher value and these products are defined as innovative. These products have a variable demand pattern but when managed appropriately in a dynamic market can win customer orders and increase the competitive advantage of the business. The base and surge demand concept as highlighted in Figure 3 [16] suggests that $70 \%$ of the base demand is usually stable and the rest being volatile. Toyota introduced one of the most distinguished LEAN systems called "Just in Time" system [17] that eliminates waste in the inventory.

However, volatile markets require an agile approach with higher flexibility. It is recommended that business adopt LEAN strategies with base demand characteristics for functional products and AGILE strategies for volatile demand characteristics for innovative products. The concept of $\mathrm{DWV}^{3}$ was introduced in 2000[18] where the demand is categorised into five different variables namely the product life cycle Duration, the time Window required for delivery, Volume, Variety and Variability. These five attributes facilitate product classification and facilitate businesses in selecting an appropriate supply chain strategy for products that can be product winners or product qualifiers [19].

It is a common practice among companies to conduct volume-variability analysis to create different distribution and manufacturing strategies in segmenting products in to different classes depending on their demand [20]. The product classification is often termed as " $\mathrm{A}$ " class products which represents the most sought products, " $B$ " class that has an intermediary demand pattern and " $\mathrm{C}$ " class implies to the less sought products. Such a volume-variability analysis facilitates companies to manage products in SKU categories based on demand and can guarantee good customer service by prioritising the manufacturing strategies on "A" class products.

\subsection{Demand Profiling approach in Segmentation}

As long as the demand signals remain as a guessing factor in businesses, excessive stocks or total stock-out cannot be ruled out. This in combination with the everchanging market dynamics and customers focussed in products with minimal lead-time, forecasting demand becomes a challenge [21]. Demand is not a single unit on a supply chain. Demand signals appears in the form of orders, forecasting tools, reserve stock calculations and is channelled and transformed by different internal production units [22]. The demand signals are just not calculated based on customer requirements based on overall sales, but they are also generated within the company's production plants as the raw materials can be refused on production with quality issues. A demand profiling approach considering the entire value-chain as shown in Figure 4 is considered for the conceptual framework.

In the demand profiling approach, the demand is segmented in to low variability and high variability demand [23]. In order to identify the variability in demand, the Coefficient of Variation (CV) needs to be determined [23]. The CV is the standard deviation of the demand within a period of time by the mean value. If the demand of the product is higher, the corresponding $\mathrm{CV}$ value will be higher. There are several academic references as highlighted in Table 1 on the threshold values of the $\mathrm{CV}$, separating from smooth demand from the erratic demand. By segmenting the demand pattern, companies can determine forecasting methods such as: statistical forecasting for demands below the cut-off value of the $\mathrm{CV}$ and manual forecasting for the any values over the cut-off [25].There are two other demand classifications namely: intermittent and lumpy [24]. The additional classifications of demand provide more clarity in demand patterns and it is achieved by squaring the squaring the $\mathrm{CV}$ value and considering the average inter-demand interval with threshold values for every single demand type.

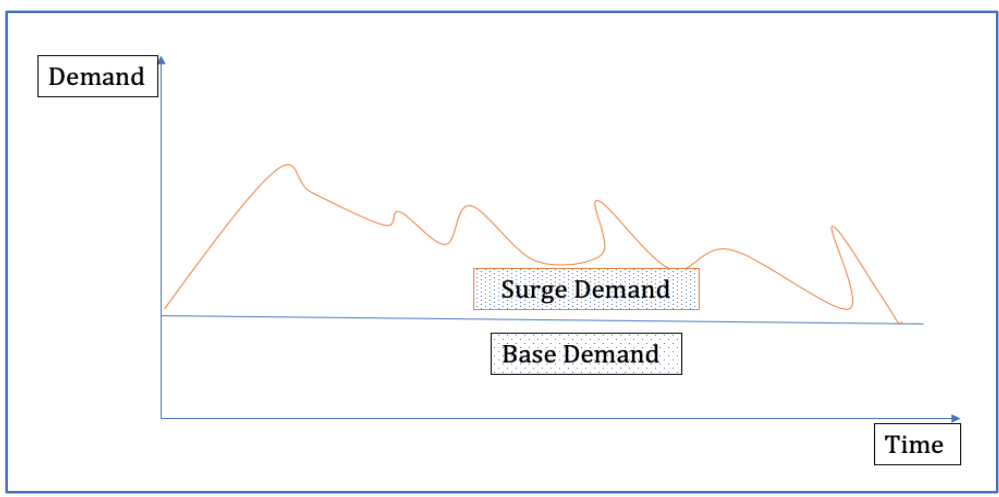

Figure 3 Demand Pattern 


\section{Table 1 Industrial Reference for $\mathrm{CV}$ threshold based on Academic references}

\begin{tabular}{|c|c|c|}
\hline Reference & Industrial Cases & CV Threshold \\
\hline$[26]$ & $\begin{array}{c}\text { All Industries } \\
\text { that use LEAN- } \\
\text { 6Sigma } \\
\text { FMCG } \\
{[12]}\end{array}$ & $\begin{array}{c}\text { Consumer goods } \\
\text { with frequent } \\
\text { seasonal } \\
\text { promotional } \\
\text { activities }\end{array}$ \\
{$[26]$} & CV cut-off $=0.4$ \\
& CV cut-off $=0.9$ \\
\hline
\end{tabular}

As shown is Figure 5, demand is classified as Erratic, Lumpy, Smooth and Intermittent with the underpinned definitions based on the $\mathrm{CV}^{2}$ threshold values:

1. $\mathrm{CV}^{2}$ threshold value for smooth is less or equal to 0.49 with the ADI cut-off being less of equal to 1.32 , indicating the demand to be stable throughout all the seasons.

2. $\mathrm{CV}^{2}$ threshold value for intermittent is less or equal to 0.49 but the ADI greater than 1.32 , indicating demand which is infrequent for a constant quantity of products.

3. $\mathrm{CV}^{2}$ threshold value for erratic is greater than 0.4 with the ADI being less of equal to 1.32, indicating demand being frequent for high variable quantity of products.

4. $\mathrm{CV}^{2}$ threshold value for lumpy is greater than 0.49 with ADI also being greater than 1.32, indicating demand being infrequent with highly variable quantity of products.

\section{CONCEPTUAL FRAMEWORK}

As shown in Figure 6, in the current demand planning processes of automobile manufacturing industry, all SKUs not segmented beyond the high volume and higher value generating SKUs with no central demand planning hub in a de-centralized planning architecture. The downstream demand variability is not included or visible within the valuechain. In the proposed conceptual framework, the overall demand from the entire value-chain is considered with one central hub where the demand data is processed to facilitate the production process. Based on the demand profiles, the SKUs are segmented, and individual manufacturing and inventory policies are set up as shown in Table 2. The demand is categorized in to four segments namely:

1. The SKUs with smooth demand profiles highlight stable demand throughout the sales period.

2. The SKUs with infrequent demand for a constant quantity of products are defined as Intermittent demand profiles.

3. The SKUs where the demand is more for high variable order size in terms of quantity of products are defined erratic demand profiles

4. The SKUs with lumpy demand profiles exhibit low frequency of demand but with high variability in the order size.

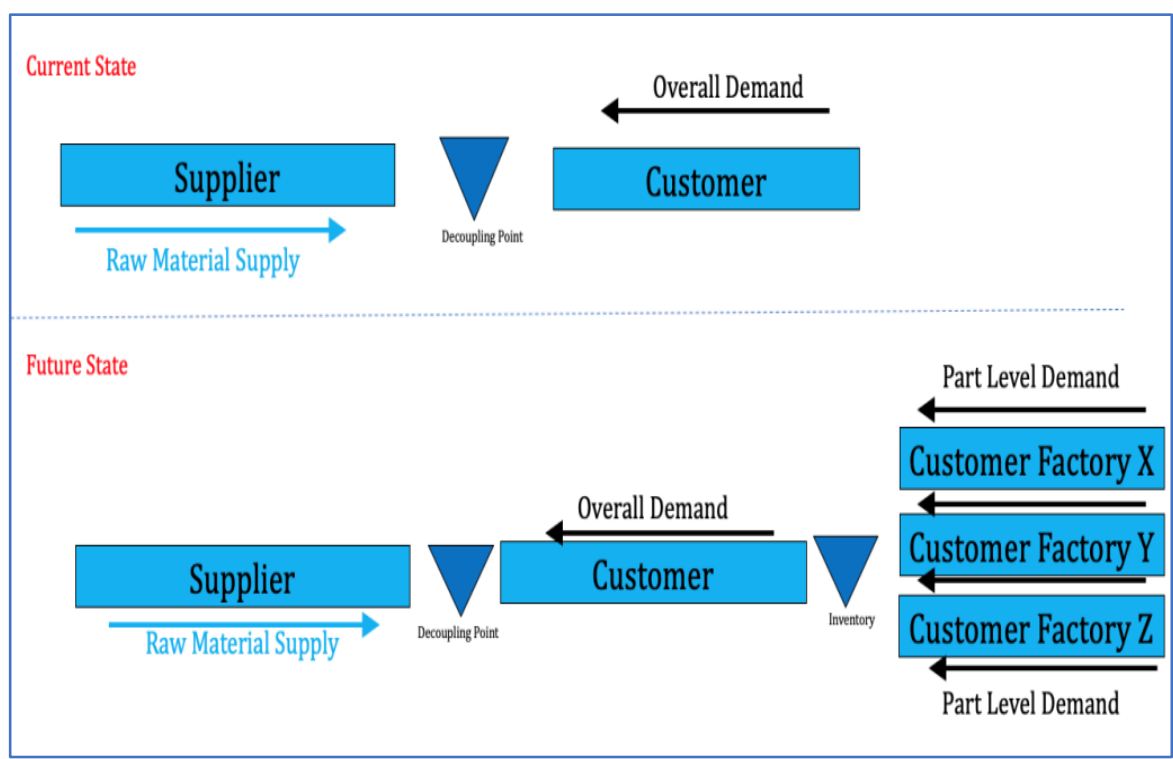

Figure 4 Demand profiling in a Value-Chain orientation 


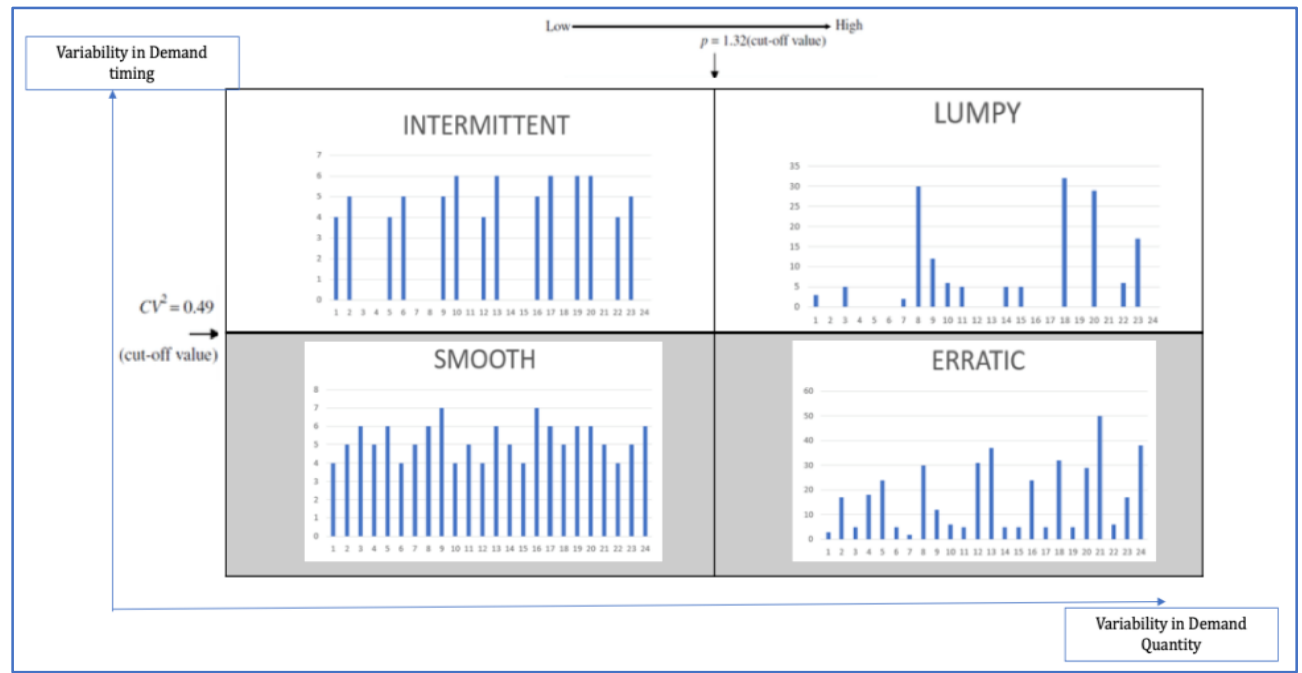

Figure 5 Categorisation of Demand based on [25]

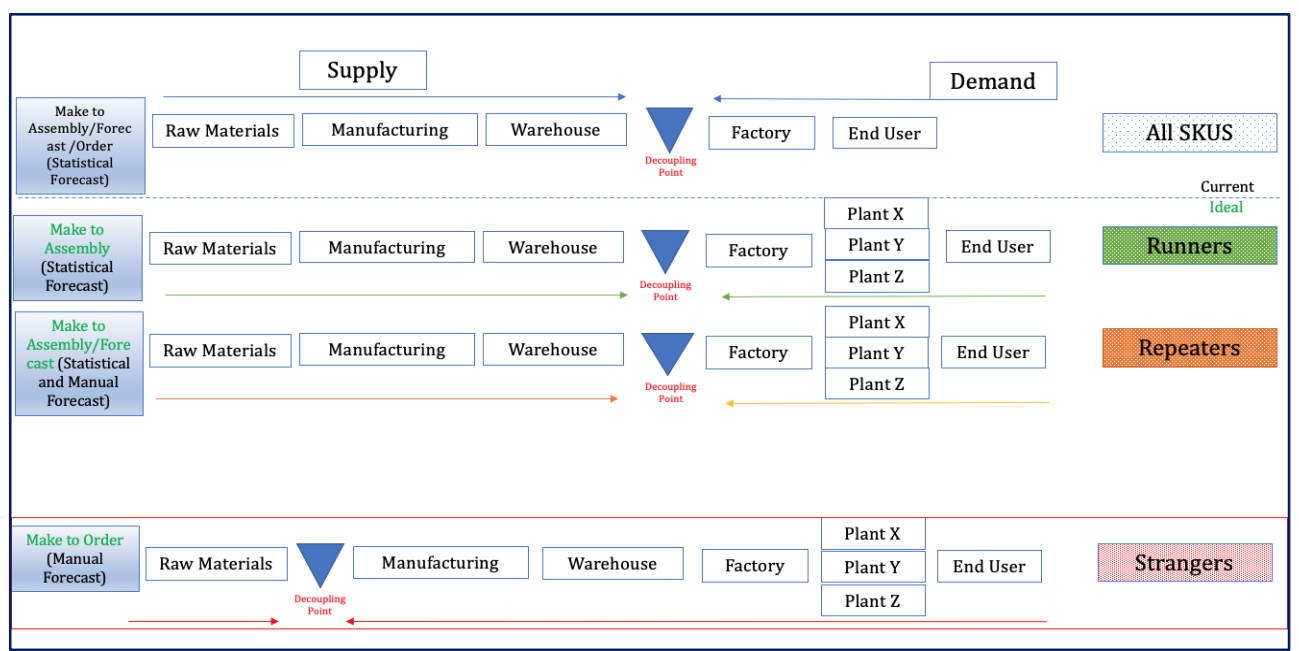

Figure 6 Conceptual Framework

Table 2 Manufacturing Strategies and Inventory Polices based on Segmentation Analysis

\begin{tabular}{|c|c|c|c|}
\hline Segment & Runner & Repeater & Stranger \\
\hline $\begin{array}{c}\text { Inventory } \\
\text { Policy }\end{array}$ & Make to Stock & $\begin{array}{c}\text { Make to } \\
\text { Forecast }\end{array}$ & $\begin{array}{c}\text { Make to } \\
\text { Order }\end{array}$ \\
\hline Forecasting & Statistical & $\begin{array}{c}\text { Manual \& } \\
\text { Statistical }\end{array}$ & Manual \\
\hline $\begin{array}{c}\text { Order } \\
\text { Strategy }\end{array}$ & $\begin{array}{c}\text { Automatic } \\
\text { order at Re- } \\
\text { order point }\end{array}$ & $\begin{array}{c}\text { Review at Re- } \\
\text { order point }\end{array}$ & Case by Case \\
\hline Review & Weekly & Monthly & Quarterly \\
\hline $\begin{array}{c}\text { Safety Stock } \\
\text { Levels }\end{array}$ & Optimal & Medium & No Stocks \\
\hline KPI & $\begin{array}{c}\text { Maintain } \\
\text { delivery } \\
\text { performance } \\
\text { and volume }\end{array}$ & Manage Risk & Manage Risk \\
\hline
\end{tabular}

Once the demand profiles are identified, the SKUs are tagged as runners, repeaters and strangers. The runner SKUs are the high value, fast-moving products with significant monetary benefits. The businesses need to employ make to stock manufacturing strategies for runner SKUS and place the inventory to closer to the de-coupling points ensuring quicker delivery performance and maximum availability of closer to the customers production facilities. For the runner SKUs, minimal management engagement is required, as repeat orders are expected in a regular basis and forecast can be performed in a statistical basis, improving the overall efficiency of the supply process. In the repeater category, higher variability of demand

\section{Rajesh \& Steffen}


in terms of volume and order frequency is expected. Due to the variability, the forecasting becomes a challenge and manual engagement is required as some products might require longer lead-times. In order to guarantee delivery performance on time and in full, the safety stock levels are set a bit higher than the runner SKUs to meet the customer service levels. The stranger SKUs are the slow-moving products with less demand. A case to case analysis can be performed for product groups falling in this category and reducing stocks for this product type can reduce significant costs to the companies. It is also easier to de-list some products falling in this category to concentrate on the repeater SKUs, improving the overall productivity of the ValueChain.

\section{CONCLUSION}

The automotive manufacturing companies and its entire value-chain of material and component suppliers cannot have a "one size-fits all" strategy in its operations management principles. In order to improve customers service levels, it is essential on the one hand to enhance delivery performance of key products that are available in-full, on-time and at the right location and on the other side to minimise supply chain costs on maintaining optimal inventory levels. It is evident that managing demand variability is the key factor in improving competitive advantage in businesses and the companies that provide their customers with products in-full despite the demand variability are set to succeed in today's competitive environment. As indicated in this paper, the segmentation principles implemented in a value-chain can significantly mitigate risks to businesses by prioritising their portfolio on highvolume and fast-moving SKUs instead of focussing on slow-moving, low-value products. The companies can plan their sourcing policies and set their manufacturing strategies in advance to tackle the demand variability. In this way, the companies are not worried about the variability, instead they are prepared for delivering products according to the needs of the customers. The proposed integrated planning hub with companies will showcase higher visibility in the entire end-end value chain with higher possibilities to track the source of the demand variability and address the root cause before it creates a bull-whip across the supply chain.

\section{REFERENCES}

[1]. Griffin-Cryan, B. et al., 2011. Lean in Supply Chain Planning. , pp.1-16.

[2]. Klappich D., 2013. Collaboration, Cloud and Evolving Strategies.

[3]. Cachon, G.P., 1999. Managing Supply Chain Demand Variability with ScheduledOrdering Policies. Management Science, 45(6), pp.843856.

[4]. New, S., 2010. The transparent supply chain. Harvard Business Review, 88(10),p.11.

[5]. Lee, H.L., Padmanabhan, V. \& Whang, S., 1997. Information Distortion in a Supply Chain: The Bullwhip Effect. Management Science, 43(4), pp.546-558.

[6]. Duran, S. et al., 2008. Policies utilizing tactical inventory for service-differentiated customers Operations Research Letters, 36(2), pp.259-264.

[7]. Sampson, S.E. \& Froehle, C., 2006. Foundations and Implications of a Proposed Unified Services Theory. Handbook of service science, 15(2), pp.329-343.

[8]. Towill, Denis R and Disney, S.., 2003. Vendor Managed Inventory and bullwhip reduction in a two level supply chain. International Journal of Production and Operations Management. Vol. 23, No. 6, pp625-651.

[9]. Christopher, M. \& Holweg, M., 2011. "Supply Chain 2.0": managing supply chains in the era of turbulence. International Journal of Physical Distribution \& Logistics Management, 41(1), pp.63-82.

[10]. Christopher, M., Peck, H. \& Towill, D.R., 2006. A taxonomy for selecting global supply chain strategies. International Journal of LogisticsManagement, 17(2), pp.277-287.

[11]. Mason-Jones, R., Naylor, B. \& Towill, D.R., 2000. Engineering the leagile supply chain. International Journal of Agile Management Systems, 2, pp.54-61.

[12]. Godsell, J. et al., 2011. Enabling supply chain segmentation through demand profiling. International Journal of Physical Distribution \& Logistics Management, 41(3), pp.296-314.

[13]. Smith, W.R., 1956. Product differentiation and market segmentation as alternative marketing strategies. The Journal of Marketing: 3-8.

[14]. Kharlamov, Alexander \& Janet Godsell 2015. Finding the needle in a haystack: an empirically tested framework for supply chain segmentation. (2015). EurOMA.

[15]. Fisher, M., 1997. What is the right supply chain for your product.pdf. Harvard Business Review, 2, pp.105-16.

[16]. Wong, C. et al., 2012. Towards a theory of supply chain alignment enablers: a systematic literature review. Supply Chain Management, 17(4), pp.419-437.

[17]. Monden, Y., 1981. Adaptable Kanbansystem helps Toyota maintain just-in time production. Industrial Engineering 13.5 (1981): 29.

[18]. Christopher, M. \& Towill, D.R., 2000. Supply chain migration from lean and functional to agile and customised. Supply Chain Management: An International Journal, 5(4), pp.206-213.

[19]. Childerhouse, P., Aitken, J. and Towill, D.R. (2002), 2002. Analysis and design of focused demand chains. Journal of Operations Management, Vol. 20 No. 6, pp. 675-89.

[20]. Vitasek, Kate L., Karl B. Manrodt, and Mark Kelly. SOLVING THE SUPPLY. Supply Chain Management Review 59 (2003).

[21]. Vitasek, K., 2016. Strategic sourcing business models. Strategic Outsourcing: An International Journal, 9(2), pp.126-138. 
[22]. Heikkilä, J., 2002. "From supply to demand chain management: efficiency and customer satisfaction." Journal of operations management 20.6 747-767.

[23]. Everitt, B.S., 2002. Cambridge Dictionary of Statistics. West Nyack.

[24]. Boylan, J.E., Syntetos, A.A. \& Karakostas, G.C., 2008. Classification for forecasting and stock control: A case study. In Journal of the Operational Research Society. pp. 473-481.
[25]. Syntetos, Boylan, J.E. \& Croston, J.D., 2004. On the categorization of demand patterns. Journal of the Operational Research Society, 56(5), pp.495503.

[26]. Wedgwood, I.D., 2006. Lean sigma: A practitioner's guide. Prentice Hall PTR,

[27]. Jüttner, U., Christopher, M. \& Godsell, J., 2010. A strategic framework for integrating marketing and supply chain strategies. The International Journal of Logistics Management, 21(1), pp.104126.

All @ 2019 are reserved by International Journal of Advanced Science and Engineering. This Journal is licensed under a Creative Commons Attribution-Non Commercial-ShareAlike 3.0 Unported License. 